\title{
COASTAL AND NAUTICAL TOURISM IN ITALIAN REGIONS
}

\author{
CORRADO RINDONE \\ Department of Information Engineering, Infrastructure and Sustainable Energy, \\ University of Mediterranean Studies of Reggio Calabria, Italy
}

\begin{abstract}
Coastal and marine tourism represents a relevant maritime economic activity. Nautical tourism is a subsector of coastal and marine tourism involving people and businesses, with relevant impacts in both the national and regional economies. The main objective of this paper is to analyze data and quantitative links between nautical tourism variables and coastal length. Among the European countries, Italy is one of the main representative member states for nautical tourism in the Mediterranean Sea. For this reason, this paper focuses specifically on the case study of Italian regions. In order to reach the objective, the paper investigates nautical tourism on the Italian coasts. Principal results of coastal supply and demand indicators are presented. These results, integrated with other nautical tourism variables and indicators, constitute some input of further quantitative analysis aiming to model this maritime segment. Further developments concerning the methods and models used will support planning of future configurations. Keywords: nautical tourism, planning, ports, supply and demand variables, tourism, transportation.
\end{abstract}

\section{INTRODUCTION}

Coastal and marine tourism is a subsector of tourism, which represents one of the largest maritime economic activities, with over 33\% of the Blue Economy in Europe. This subsector was included in the "European Strategy for more Growth and Jobs in Coastal and Maritime" areas. The European strategy has three actions: island connectivity, tourism diversification strategies and innovative strategies for nautical tourism [1].

Nautical tourism, the focus of this paper, is a sector of coastal and marine tourism. In Europe, the sector involves about 36 million people whom practice boating regularly, with 6 million boats and some 4,500 marinas employing approximately 40,000-70,000 people [2]. The Mediterranean Sea is one of the main destinations for nautical tourists, with significant economic impact for coastal cities [3]. Italy, which has a coastal extension about 7,500 km, is one of the main destinations for nautical tourism in the Mediterranean Sea [4]. Despite the nautical tourism relevance, this is an under-exploited research area [5].

Nautical tourism represents an intersection among three sectors related to transport, travel and tourism [6]. By focusing on the maritime transport and travel sectors, it is necessary to distinguish freight from people mobility. Freight maritime mobility comprehends shipping on deep-sea routes [7] and short-sea shipping [8]. Passenger mobility comprehends both travel for business, and for leisure and tourism. A first set of basic variables of nautical tourism was analyzed by Russo and Rindone [9]. An extended analysis of nautical tourism and coastal supply is needed, in order to estimate the impacts deriving from interactions between the touristic ports and their surrounding territories [10], [11].

In this context, and with specific reference to the Italian regional territories, the objective of this paper was to analyze the interrelations between nautical tourism and coastal characteristics in terms of length, linking demand and supply. The paper's final aim is to represent the current situation of nautical tourism in the Italian regions, in relation to the Italian coastal extension. Information about the infrastructure, services and users of nautical tourism in Italy, derived from public and private sources, are elaborated upon in order to obtain quantitative indicators. In Italy, data on nautical tourism can be obtained from 
maritime public authorities (e.g. the Italian Ministry of Infrastructure and Transport (MIT) [12]), and maritime private operators (UCINA [13], INGEMAR [14], CNA [15], and the Pagine Azzurre (blue pages) [16]). They collect information relative to:

- Nautical supply (infrastructure and services), comprehension of information on berths, moorings and equipment;

- Boating demand, with information on:

- registered vessels, classified for their type of propulsion (motorboats, sailboats) and class length; and

- nautical licenses, classified by the authorized driving distance from the coast.

For an analysis of public and private data sources, see Russo and Rindone [9]. An analysis of the available data provides the principal results about the current configuration of nautical tourism in Italy. These results, integrated with other variables and information, constitute the inputs for further quantitative analyses, aiming to measure port efficiency [17], [18] and build the modeling tools [19]-[21] needed to gain insight on topics related to nautical tourism.

The paper, other than the introduction, is composed of three sections. Section 2 describes coastal variables related to infrastructure, services (transport supply) and nautical tourism demand. Section 3 reports on the principal indicators of coastal variables, related to nautical tourism, with a specific focus on the Italian regions. Section 4 reports the preliminary conclusions, with some projection for a future scenario.

\section{METHODS}

\subsection{Coastal variables}

The information and data obtained from public and private sources allow the definition of some coastal variables that identify the nautical tourism characteristics in Italy. Section 2.2 reports on socioeconomic and territorial variable definitions. Section 2.3 reports on the supply and demand variables' definitions, with a specific reference to the available information deriving from national authorities.

\subsection{Socioeconomic and territorial variables}

Selected socioeconomic and territorial variables were collected for each Italian region, and for the regions with a coastline. By defining $R$ as the full set of Italian regions, the following sets were considered:

- $R T$ the set of regions with a coastline;

- $R N$ the set of regions with no coastline;

- $C N$ the set of $R T$ located in the center-north of Italy (Liguria, Tuscany, Lazio, Marche, Emilia Romagna, Veneto, Friuli Venezia Giulia - Friuli VG);

- SI, the set of RT located in the south of Italy (Campania, Calabria, Puglia, Molise, Abruzzo, Sardinia and Sicily).

Note that:

$R T \subset R$;

$R N \subset R$;

$R=R T \cup R N$

$R T=C N \cup S I$. 
For each Italian region $r(r \in R)$ it is possible to consider the following variables:

- pop $_{r}$, the population in the region $r$;

- $\quad$ inc $_{r}$, the average income of the population in the region $r$;

- $k m_{r}$, the coastal extension of the region $r$, expressed in kilometers.

\subsection{Supply and demand variables}

By considering the sets identified in Section 2.2 and the MIT database [12] from 2016, the following supply and demand variables were defined:

- $l_{r}$, total number of nautical licenses in the region $r$; the variable is available in relation to the licence class, which vary in function of the allowed navigation distance from the coast (a) within 12 miles or (b) without limitations);

- $b_{r}$, total number of nautical boats registered in the region $r$; this variable is available in relation to:

- Boat length $l(l<10 \mathrm{~m} ; 10<l<24 \mathrm{~m} ; l>24 \mathrm{~m})$;

- Typology of engine (motorboats; sailing boats);

- $n b_{r}$, the total number of nautical berths in the $r$ with

- $n b_{r} \neq 0$ for $r \in R T$,

- $n b_{r}=\emptyset$ for the others.

This variable is available in relation to:

- Type of port (marina, multi-purpose ports, mooring points);

- Mooring berth capacity, measured in boat-length terms ( $<10 \mathrm{~m} ; 10-24 \mathrm{~m} ;>24 \mathrm{~m})$.

\section{RESULTS AND AGGREGATE COASTAL INDICATORS}

Elaborations of available data, derived from selected sources, provide aggregate coastal indicators of nautical tourism at the regional level. Starting from a selection of the variables defined in Section 2.3, the aggregate indicators relative to supply (Section 3.1) and demand (Section 3.2) subsystems of the Italian regions were calculated.

\subsection{Supply indicators}

Selected variables linking supply and coastal data were elaborated in order to obtain aggregate indicators:

- Availability of nautical berths per $\mathrm{km}$ of coast for each region:

$$
N B K_{r}=\frac{n b_{r}}{k m_{r}} \forall r \in R T .
$$

- Average availability of nautical berths per $\mathrm{km}$ of coast, in relation to the regional sets defined in Section $2.2(R T, C N, S I)$ :

$$
\overline{N B K}_{R T}=\frac{1}{N_{R T}} \sum_{\mathrm{r} \in R T} N B K_{r},
$$




$$
\begin{gathered}
\overline{N B K}_{C N}=\frac{1}{N_{C N}} \sum_{\mathrm{r} \in C N} N B K_{r}, \\
\overline{N B K}_{S I}=\frac{1}{N_{S I}} \sum_{\mathrm{r} \in S I} N B K_{r},
\end{gathered}
$$

where $N_{R T}, N_{C N}$ and $N_{S I}$ are the numbers of elements within each set;

- Percentage of nautical berths per $\mathrm{km}$ of coast, with respect to average values referred to each set as defined in Section 3.1:

$$
\begin{gathered}
P N B K_{R T, r}=\frac{N B K_{\mathrm{r}}}{\overline{N B K}_{R T}} \forall r \in R T, \\
P N B K_{C N, r}=\frac{N B K_{\mathrm{r}}}{{\overline{N B K_{C N}}}_{\mathrm{A}}} \forall r \in C N, \\
P N B K_{S I, r}=\frac{N B K_{\mathrm{r}}}{{\overline{N B K_{S I}}}_{\mathrm{S}}} \forall r \in S I .
\end{gathered}
$$

Table 1 reports values of the supply indicators.

Table 1: Supply indicators for the Italian regions: nautical berths per kilometer of coast.

\begin{tabular}{clccc}
\hline & Regions & $N B K_{r}$ & $P N B K_{C N, r}$ & $P N B K_{R T, r}$ \\
\hline & Liguria & 72.64 & 1.30 & 2.10 \\
Tuscany & 31.23 & 0.56 & 0.90 \\
\multirow{3}{*}{ Lazio } & 23.84 & 0.43 & 0.69 \\
Marche & 30.75 & 0.55 & 0.89 \\
& Emilia Romagna & 40.96 & 0.73 & 1.19 \\
Veneto & 41.15 & 0.74 & 1.19 \\
Friuli VG & 149.62 & 2.68 & 4.34 \\
\hline \multicolumn{5}{c}{$\overline{N B K}_{C N}=55.74$} \\
\\
\hline
\end{tabular}

Fig. 1 depicts the percentage of nautical berths per km of coast $P N B K_{R T, r}$. Note that the highest values are relative to regions located in the northern territories. For these regions, the average quantity of nautical berths per $\mathrm{km}$ of coast $\left(\overline{N B K}_{C N}\right)$ is $60 \%$ higher than the national average value $\left(\overline{N B}_{R T}\right)$. By considering this indicator, two regions (Liguria and Friuli VG) register a number of nautical berths per $\mathrm{km}$ that is the highest, with values about two times 
(Liguria) or four times (Friuli VG) higher than the Italian average. The Liguria region registers the highest value of nautical berths in Italy. Among the southern regions, Campania has values approximately similar to the Italian average value, and is double when compared to the average SI value.

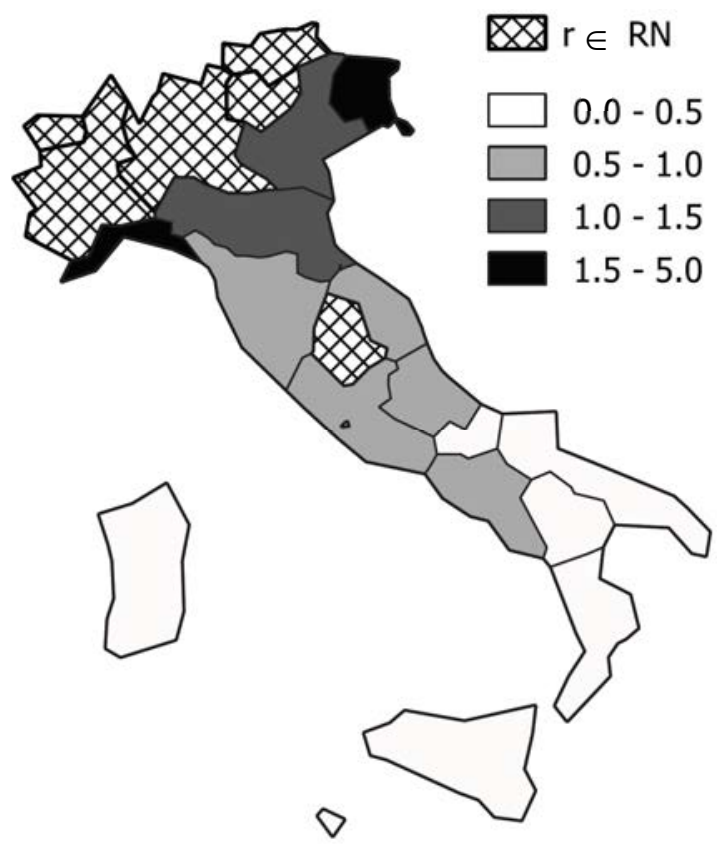

Figure 1: Percentage of nautical berths per $\mathrm{km}$ of coast $P N B K_{\mathrm{RT}, \mathrm{r}}$.

Two different factors can influence these results:

- An economic factor relative to the different levels of average income between the North and the South;

- A geographic factor relative to the administrative borders of the regions; in fact, Fig. 1 shows the other regions which belong to the set RN that are potentially included in the attraction area of the regions with a coastline.

\subsection{Demand indicators}

Selected variables related to the demand subsystem were elaborated on, in order to obtain two sets of aggregate demand indicators (Table 2).

The first set of demand indicators is:

- Nautical licenses per $\mathrm{km}$ of coast for each region:

$$
K N L_{r}=\frac{l_{r}}{k m_{r}} \forall r \in R T \text {. }
$$


- Average availability of nautical licenses per $\mathrm{km}$ of coast in relation to the regional sets defined in Section $2.2(R T, C N, S I)$ :

$$
\begin{aligned}
\overline{K N L}_{R T} & =\frac{1}{N_{R T}} \sum_{\mathrm{r} \in R T} K N L_{r,} \\
\overline{K N L}_{C N} & =\frac{1}{N_{C N}} \sum_{\mathrm{r} \in C N} K N L_{r,} \\
\overline{K N L}_{S I} & =\frac{1}{N_{S I}} \sum_{\mathrm{r} \in S I} K N L_{r} .
\end{aligned}
$$

- Percentage of nautical licenses per $\mathrm{km}$ of coast, with respect to average values referring to each set defined in Section 2.2:

$$
\begin{gathered}
P K N L_{R T, r}=\frac{K N L_{\mathrm{r}}}{\overline{N L}_{R T}} \forall r \in R T, \\
P K N L_{C N, r}=\frac{K N L_{\mathrm{r}}}{\overline{K N L}_{C N}} \forall r \in C N, \\
P K N L_{S I, r}=\frac{K N L_{\mathrm{r}}}{\overline{K N L}_{S I}} \forall r \in S I .
\end{gathered}
$$

\begin{tabular}{|c|c|c|c|c|}
\hline & Regions & $K N L_{r}$ & $P K N L_{C N, r}$ & $P K N L_{R T, r}$ \\
\hline \multirow{7}{*}{ z } & Liguria & 25.25 & 1.78 & 2.96 \\
\hline & Tuscany & 5.19 & 0.36 & 0.61 \\
\hline & Lazio & 9.68 & 0.68 & 1.13 \\
\hline & Marche & 6.91 & 0.49 & 0.81 \\
\hline & Emilia Romagna & 19.17 & 1.35 & 2.25 \\
\hline & Veneto & 13.93 & 0.98 & 1.63 \\
\hline & Friuli VG & 19.40 & 1.36 & 2.27 \\
\hline \multicolumn{5}{|c|}{$\overline{K N L}_{C N}=14.22$} \\
\hline & & $K N L_{r}$ & $P K N L_{S I, r}$ & $P K N L_{R T, r}$ \\
\hline \multirow{8}{*}{$\bar{n}$} & Basilicata & 1.59 & 0.59 & 0.20 \\
\hline & Campania & 7.06 & 2.63 & 0.87 \\
\hline & Calabria & 1.38 & 0.51 & 0.17 \\
\hline & Puglia & 1.71 & 0.64 & 0.21 \\
\hline & Molise & 1.19 & 0.44 & 0.15 \\
\hline & Abruzzo & 4.23 & 1.57 & 0.52 \\
\hline & Sardinia & 1.43 & 0.53 & 0.18 \\
\hline & Sicily & 2.93 & 1.09 & 0.36 \\
\hline \multicolumn{5}{|c|}{$\overline{K N L}_{S I}=2.69$} \\
\hline \multicolumn{5}{|c|}{$\overline{K N L}_{R T}=8.07$} \\
\hline
\end{tabular}

Fig. 2 depicts the percentage of nautical licenses per km of coast $P K N L_{R T, r}$.

Table 2: Demand indicators for the Italian regions: nautical licenses per kilometer of coast. 


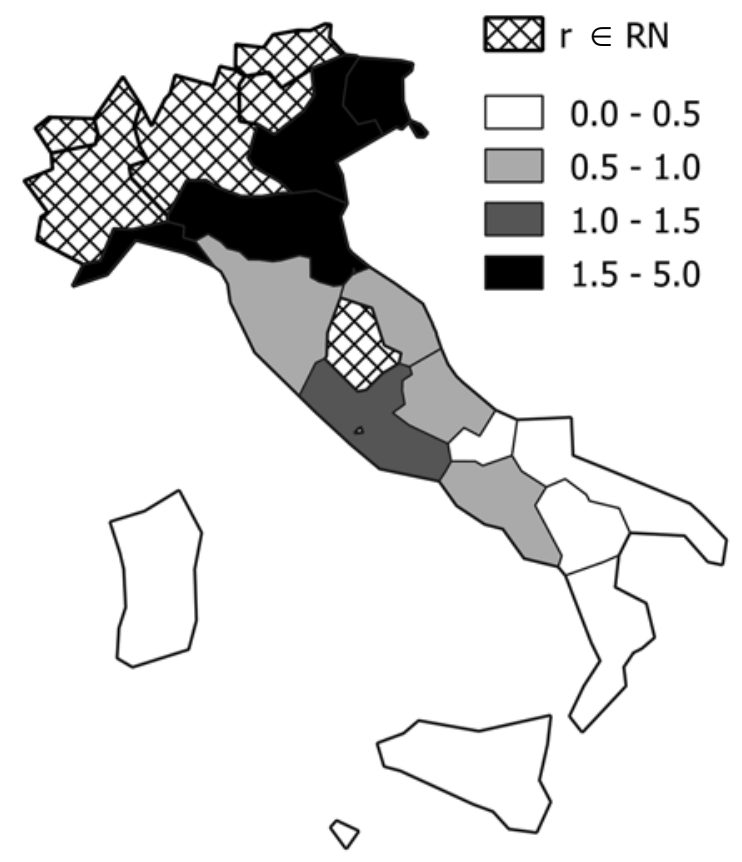

Figure 2: Percentage of nautical licenses per kilometer of coast $P K N L_{R T, r}$.

The second set of demand indicators comprehends:

- Boats per km of coast:

$$
B K_{r}=\frac{b_{r}}{k m_{r}} \forall r \in R T \text {. }
$$

- Average availability of nautical boats per $\mathrm{km}$ of coast, in relation to the regional sets defined in Section $2.2(R T, C N, S I)$ :

$$
\begin{aligned}
\overline{B K}_{R T} & =\frac{1}{N_{R T}} \sum_{\mathrm{r} \in R T} B K_{r}, \\
\overline{B K}_{C N} & =\frac{1}{N_{C N}} \sum_{\mathrm{r} \in C N} B K_{r}, \\
\overline{B K}_{S I} & =\frac{1}{N_{S I}} \sum_{\mathrm{r} \in S I} B K_{r} .
\end{aligned}
$$

- Percentage of nautical boats per km of coast with respect to average values referred to in each set defined in Section 2.2:

$$
P B K_{R T, r}=\frac{B K_{\mathrm{r}}}{\overline{B K}_{R T}} \forall r \in R T,
$$




$$
\begin{gathered}
P B K_{C N, r}=\frac{B K_{\mathrm{r}}}{\overline{B K}_{C N}} \forall r \in C N, \\
P B K_{S I, r}=\frac{B K_{\mathrm{r}}}{\overline{B K}_{S I}} \forall r \in S I .
\end{gathered}
$$

Table 3 reports the values of the second set of demand indicators calculated for the Italian coastal regions within the regional sets that were previously introduced. Note that, like in the case of supply, the first set of demand indicators shows two regions (Liguria and Friuli VG) having values higher than the average values of our selected set.

\begin{tabular}{|c|c|c|c|c|}
\hline & Regions & $B K_{r}$ & $P B K_{C N}$ & $P B K_{R T, r}$ \\
\hline \multirow{7}{*}{ Z } & Liguria & 53.52 & 20.25 & 2.75 \\
\hline & Tuscany & 17.57 & 6.65 & 0.90 \\
\hline & Lazio & 32.85 & 12.43 & 1.69 \\
\hline & Marche & 18.40 & 6.96 & 0.95 \\
\hline & Emilia Romagna & 37.43 & 14.16 & 1.93 \\
\hline & Veneto & 41.05 & 15.53 & 2.11 \\
\hline & Friuli VG & 36.93 & 13.97 & 1.90 \\
\hline \multicolumn{5}{|c|}{$\overline{B K}_{C N}=33.96$} \\
\hline & & $B K_{r}$ & $P B K_{S I}$ & $P B K_{R T, r}$ \\
\hline \multirow{8}{*}{$\bar{s}$} & Basilicata & 1.62 & 0.24 & 0.08 \\
\hline & Campania & 32.22 & 4.80 & 1.66 \\
\hline & Calabria & 1.37 & 0.20 & 0.07 \\
\hline & Puglia & 3.60 & 0.54 & 0.19 \\
\hline & Molise & 1.78 & 0.26 & 0.09 \\
\hline & Abruzzo & 6.99 & 1.04 & 0.36 \\
\hline & Sardinia & 2.78 & 0.41 & 0.14 \\
\hline & Sicily & 3.38 & 0.50 & 0.17 \\
\hline \multicolumn{5}{|c|}{$\overline{B K}_{S I}=6.72$} \\
\hline \multicolumn{5}{|c|}{$\overline{B K}_{R T}=19.43$} \\
\hline
\end{tabular}

Table 3: Demand indicators for the Italian regions: boats per kilometer of coast.

The values of demand indicators, like supply indicators, show the divergence between $C N$ and SI regions. The two sets of demand indicators have values higher than the $C N$ average values and national average values.

By considering the first set of demand indicators, the $C N$ regions register an average value of nautical licenses per $\mathrm{km}$ of coast higher than five times the SI value. The value indicator for the Liguria region is about $80 \%$ higher than the $C N$ average value. Regions belonging to the SI set, excluding Campania, Abruzzo and Sicily, register about less than one unit of nautical license per $\mathrm{km}$ of coast (Table 2).

By considering the second set of demand indicators, the $C N$ regions register an average number of boats per $\mathrm{km}$ of coast five times higher than the SI value (Table 3). Note that the high difference also depends on the Italian nautical rules for which a vessels' registration, if under $10 \mathrm{~m}$, is optional.

Considering the lower average income in the southern compared to the northern regions, it could be possible that in the south there is a great number of vessels with a length under $10 \mathrm{~m}$. Fig. 3 depicts the percentage of nautical boats per kilometer of coast $P B K_{R T, r}$. 


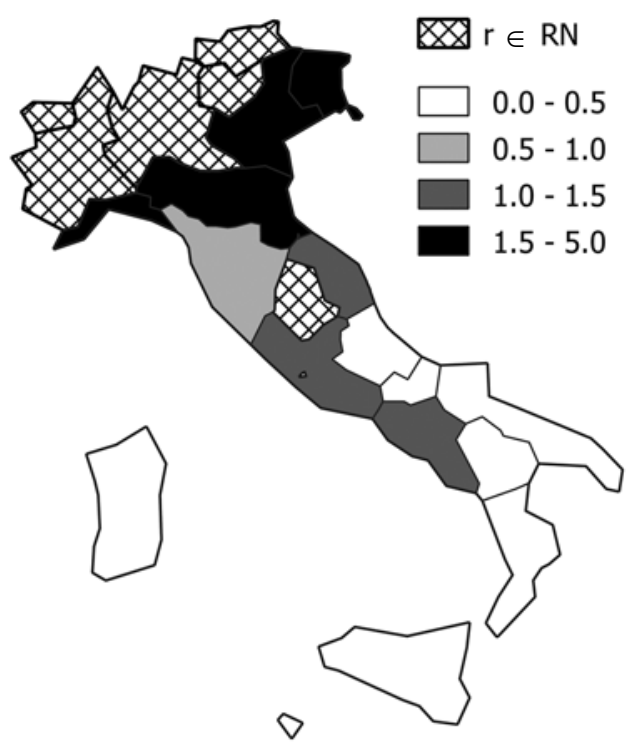

Figure 3: Percentage of nautical boats per kilometer of coast, $P B K_{R T, r}$.

\section{CONCLUSIONS}

This paper presents an analysis of nautical tourism and coastal extension in Italy. The author gained insights about the main data and quantitative links between nautical tourism variables and coastal length. We introduce some indicators in relation to their demand/supply components. The results show a divergence in assets with regards to nautical tourism in the regions with a coastline. There is also divergence between northern and southern regions, in terms of nautical supply, as measured in terms of nautical berths, nautical licenses and nautical boat quantities, with respect to the coast. Table 4 reports simulated scenarios for the SI set under different assumptions for nautical berths. by projecting current scenario values.

Table 4: $\quad$ Simulated scenarios for the SI set: ${ }^{a}$ By projecting the current scenario's values with the indicator $\overline{N B K}_{R T}=34.51$; ${ }^{\text {b } B y ~ p r o j e c t i n g ~ t h e ~ c u r r e n t ~ s c e n a r i o ' s ~ v a l u e s ~}$ with the indicator $\overline{N B K}_{C N}=55.74$.

\begin{tabular}{lcccc}
\hline Regions & $k m_{r}$ & $\begin{array}{c}\text { Current } \\
\text { scenario }\end{array}$ & $\begin{array}{c}\text { Simulated } \\
\text { scenario } R T^{\mathrm{a}}\end{array}$ & $\begin{array}{c}\text { Simulated } \\
\text { scenario } C N^{\mathrm{b}}\end{array}$ \\
\cline { 2 - 5 } & $n b_{r}{ }^{a} 10^{3}$ & $n b_{r}{ }^{a} 10^{3}$ & $n b_{r}{ }^{a} 10^{3}$ \\
\hline Basilicata & 62.20 & 1.03 & 2.15 & 3.47 \\
Campania & 469.70 & 14.74 & 16.21 & 26.18 \\
Calabria & 715.70 & 4.63 & 24.70 & 39.89 \\
Puglia & 865.00 & 12.41 & 29.85 & 48.22 \\
Molise & 35.40 & 0.59 & 1.22 & 1.97 \\
Abruzzo & 125.80 & 2.70 & 4.34 & 7.01 \\
Sardinia & 1731.10 & 17.58 & 59.75 & 96.49 \\
Sicily & 1483.90 & 15.69 & 51.21 & 82.71 \\
\hline
\end{tabular}


This nautical data, weighted for coastal data and relative indicators, could be useful in transportation planning processes aiming to promote nautical tourism and its potential for surrounding port areas. This process can aim to increase the competitiveness of the southern regions.

The current values of the indicator $n b_{r}$ are projected in different scenarios, assuming for the SI set the indicator $\overline{N B K}_{R T}=34.51$ (Simulated scenario $R T$ ) and the indicator $\overline{N B K}_{C N}=$ 55.74 (Simulated scenario $C N$ ). From these preliminary results, emerges that there is a severe lack of nautical berths in Southern Italy.

Further analyses need to link the nautical variables with:

- The population distribution and implicit population, considering the border regions with no coastline;

- The average income of the region;

- The accessibility of the region by the main touristic nautical flows.

\section{ACKNOWLEDGEMENT}

The author would like to thank MIT (the Ministry of Infrastructure and Transport of Italy) for the precious data and information provided for this research.

\section{REFERENCES}

[1] European Commission, A European strategy for more growth and jobs in coastal and maritime tourism, 2014, Online. https://publications.europa.eu/en/publication-detail//publication/88073fdf-4333-4d45-a012-aff4eeflbf3b. Accessed on: Jul. 2019.

[2] European Commission, Executive Agency for Small and Medium-sized Enterprises (EASME), Study on specific challenges for a sustainable development of coastal and maritime tourism in Europe. European Union, 2016. ISBN 978-92-9202-190-0. DOI: $10.2826 / 94993$.

[3] ECORYS, Study in support of policy measures for maritime and coastal tourism at EU level, 2013, Online. https://ec.europa.eu/maritimeaffairs/sites/maritimeaffairs/files/ docs/body/study-maritime-and-coastal-tourism_en.pdf. Accessed on: Jul. 2019.

[4] Benevolo, C. \& Spinelli, R., The quality of web communication by Italian tourist ports. Tourism: An International Interdisciplinary Journal, 66(1), 2018.

[5] González, Y.E.L., Ledesma, D.L. \& León González, J., European nautical tourists: Exploring destination image perceptions. Tourism and Hospitality Management, 21(1), pp. 33-49, 2015.

[6] Diakomihalis, M.N., Greek maritime tourism: evolution, structures and prospects. Research in Transportation Economics, 21, pp. 419-455, 2007.

[7] Russo, F., Musolino, G. \& Assumma, V., Competition between ro-ro and lo-lo services in short sea shipping market: The case of Mediterranean countries. Research in Transportation Business and Management, 19, pp. 27-33, 2016.

[8] Russo, F., Musolino, G. \& Assumma, V., An integrated procedure to estimate demand flows of maritime container transport at international scale. International Journal of Shipping and Transport Logistics, 6(2), pp. 112-132, 2014.

[9] Russo, F. \& Rindone, C., Nautical tourism and regional population: The Italian case. WIT Transactions, in press, 2019.

[10] Russo, F. \& Musolino, G., A unifying modelling framework to simulate the Spatial Economic Transport Interaction process at urban and national scales. Journal of Transport Geography, 24, pp. 189-197, 2012. 
[11] Musolino, G., Rindone, C. \& Vitetta, A., Passengers and freight mobility with electric vehicles: A methodology to plan green transport and logistic services near port areas. Transportation Research Procedia, 37, pp. 393-400, 2019.

[12] Ministero delle Infrastrutture e dei Trasporti (MIT), Diporto Nautico in Italia - Anno 2016 [Nautical Sports in Italy - 2016], 2016, Online. http://www.mit.gov.it/diportonautico-italia-2016. Accessed on: May 2019.

[13] UCINA, Confindustria Nautica. La nautica in cifre. Trend di mercato per l'anno 2018, 2018, Online. http://www.lanauticaincifre.it/pubblicazioni/. Accessed on: Jun. 2019.

[14] Ingegneria Marittima (INGEMAR), "Marina d'Italia 2017" Parziale estratto in collaborazione con Barche a Motore e Il Giornale della Vela, 2017, Online. http://www.ali6.org/\#archivio. Accessed on: May 2019.

[15] Confederazione Nazionale dell'Artigianato e della Piccola e Media Impresa (CNA) [National Confederation of Artisans and Small and Medium Business], Dinamiche e prospettive di mercato della filiera nautica da diporto [Dynamics and market perspective for nautical sports], 2017, Online. http://www.cna.it/centrostudi/notizie/2017dinamiche-e-prospettive-di-mercato-della-filiera-nautica-dadiporto\#.WvAkloiFPcs. Accessed on: May 2018.

[16] PagineAzzurre.it, 2018, Online. Accessed on: Jun. 2019.

[17] Russo, F. \& Rindone, C., Data Envelopment Analysis (DEA) for evacuation planning. WIT Transactions on Information and Communication Technologies, vol. 43, pp. PI455-PI467, 2010.

[18] Russo, F. \& Rindone, C., Container maritime transport on an international scale: Data envelopment analysis for transhipment port. WIT Transactions on Ecology and the Environment, vol. 150, WIT Press: Southampton and Boston, pp. 831-843, 2011.

[19] Cascetta, E., Optimization and its applications. Transportation Systems Analysis. Models and Applications, Springer, 2009. DOI: 10.1007/978-0-387-75857-2

[20] Ortuzar, J.D.D. \& Willumsen, L.G., Modelling Transport, Wiley, 2011. DOI:10.1002/9781119993308

[21] Vitetta, A., A quantum utility model for route choice in transport systems. Travel Behaviour and Society, 3, pp. 29-30, 2016. 